\title{
A Diode-Laser-System for Laser-Assisted Bending of Brittle Materials
}

\author{
F. Bammer, ${ }^{1}$ D. Schuöcker, ${ }^{2}$ T. Schumi, ${ }^{1}$ B. Holzinger, ${ }^{1}$ and G. Humenberger ${ }^{1}$ \\ ${ }^{1}$ Institute of Production Engineering and Laser Technology, Vienna University of Technology, Gusshausstr 30, \\ A-1040 Vienna, Austria \\ ${ }^{2}$ Oberösterreichisches Laserzentrum, Gaswerkgasse 4, A-4810 Gmunden, Austria
}

Correspondence should be addressed to F. Bammer, bammer@ift.at

Received 15 February 2011; Accepted 20 May 2011

Academic Editor: José Luis Ocaña-Moreno

Copyright () 2011 F. Bammer et al. This is an open access article distributed under the Creative Commons Attribution License, which permits unrestricted use, distribution, and reproduction in any medium, provided the original work is properly cited.

\begin{abstract}
We developed a small and compact system of diode lasers, which can be inserted into the lower tools of a bending press. The parts of the system allow easy plug and play operation and can be installed for any bending length. The diode laser, which is based on $200 \mathrm{~W}$ laser bars on microchannel cooler, allows the heating of sheet metals in the forming zone shortly before and during the bending process. There is no unnecessary heating of other parts of the bending equipment, no wear of the tool, and, if properly done, no damage of the surface of the metal. The power per bending length is $16 \mathrm{~kW} / \mathrm{m}$.
\end{abstract}

\section{Introduction}

The production of complex structures out of sheet metals with bending technology is widespread in industry. Alas, this is currently mainly restricted to materials that allow a certain degree of cold forming. Brittle materials, as $\mathrm{Mg}$-, Ti-, or some $\mathrm{Al}-$ and steel-alloys are generally avoided or, in some rare cases, heated up as a whole, before the bending operations are performed. Due to fast cooling the initial temperatures must exceed the necessary forming temperatures, such that the whole process becomes very cumbersome. The goal of laser assisted bending, not to be confused with laser-bending [1], is to make bending of brittle materials nearly as simple as cold bending by selective heating of the work piece with a laser source shortly before and during the bending process.

Previous work [2] uses a $\mathrm{CO}_{2}$ Laser to heat up bending lengths up to $1 \mathrm{~m}$ with a scanner system. Another approach was the use of a diode laser, again with a scanner system [3].

In order to obtain a system for industrial use, we developed a diode laser system based on diode laser bars on microchannel coolers. The system can be installed inside a special tool, which replaces the lower tool of a bending press. The challenge here was that on smallest possible space, a dust-tight solution with optics, power and cooling water supply was to be integrated. Furthermore, the solution should allow any required bending length to be installed.

\section{The Laser Source}

Diode laser bars [4] with an optical power of $200 \mathrm{~W}$ and a wavelength of $940 \mathrm{~nm}$ are used. The current consumption of one bar is $220 \mathrm{~A}$ and the voltage drop is $\sim 2 \mathrm{~V}$. The bars are soldered on microchannel coolers, eight of which fit into a lower tool for $100 \mathrm{~mm}$ bending length, which yields an optical power of $16 \mathrm{~kW} / \mathrm{m}$. The diode laser rests on the bottom of the lower tool, which consist of two parts. The screws, that fix them, are located above the diode lasers. Figure 1 shows two solutions for guiding the laser radiation around these screws. On the left, reflecting distance holders are used, such that the reflected beam hits the shadowed region above the neighbor-distance holder. The beams of the lasers $1,4,5$, and 8 are reflected, such that they hit the work piece in areas above the distance holders and the connection screws. The center reflecting surfaces should be curved or should have a kink in the middle (as shown) such that the reflected beams are focused to fill exactly the shadowed areas above the side distance holders. The solution on the right uses prisms that cross the beams such that not illuminated space for screws and distance holders is generated. The prism solution allows obviously more screws and is currently preferred.

Figure 2 shows the mounting of microchannel coolers on the base part (made of the plastic PEEK), which contains the channels for cooling water supply. 


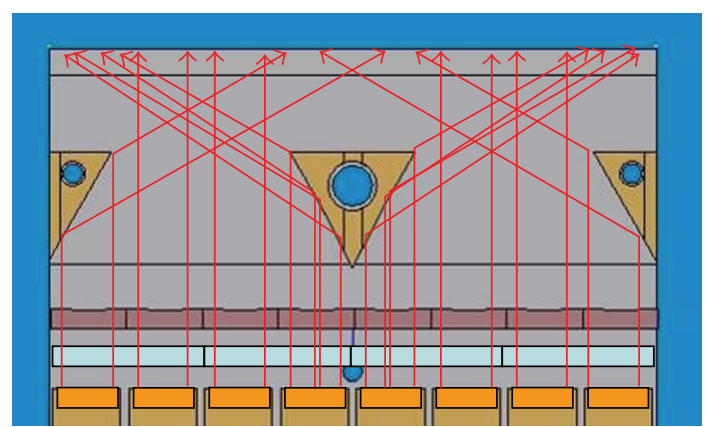

(a)

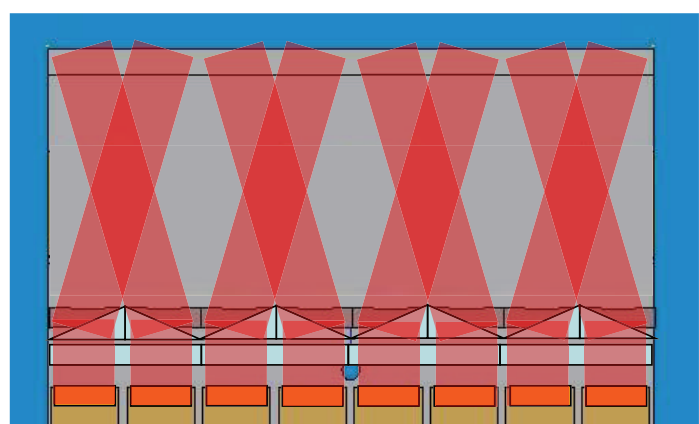

(b)

FIGURE 1: Optical beam guidance around the connections screws. (a) With reflecting distance elements for lasers 1, 4, 5, 8. (b) with prisms crossing two neighbored beams.

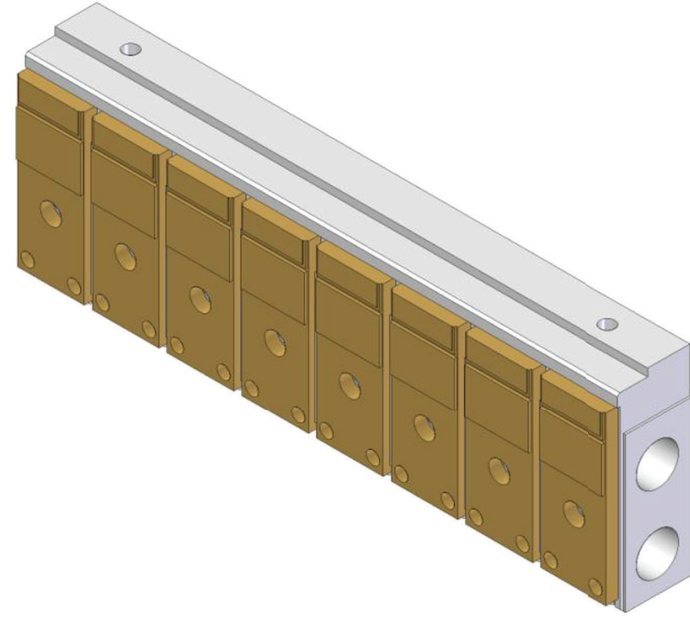

FIGURE 2: $1.6 \mathrm{~kW}$ diode laser: mounting of 8 micro-channel coolers on the base part.

$\mathrm{Cu}$-connectors fix the lasers and provide a serial connection as shown in Figure 3 together with the FAC lenses and the prisms.

To enable a compact design, the casing is made of two parts, each of which has a contact to the first and the last diode laser bar, respectively, and contains the connectors to the neighbor lasers or to the power supply (Figure 4). Casing parts of neighbored diode lasers are electrically connected via three plugs (Figures 4 and 6). To protect the optics from dirt falling down from the work piece, a protection glass is inserted. Thin side covers finish the diode laser that can now be inserted into the lower tool (Figure 4).

The lower tool consists of two parts and contains a cavity for the diode laser, which can be inserted from the side or from the front. (Figure 5, the view in Figures $2-5$ is from the machine side.)

Figure 6 shows a finished laser for $100 \mathrm{~mm}$ bending length from the front side, showing the electrical connectors. Similar devices were built for $50 \mathrm{~mm}$ bending length and such for $25 \mathrm{~mm}$ are planned such that some flexibility is possible. Many bending applications, for example, for casings, demand an accurate setup of certain bending lengths.

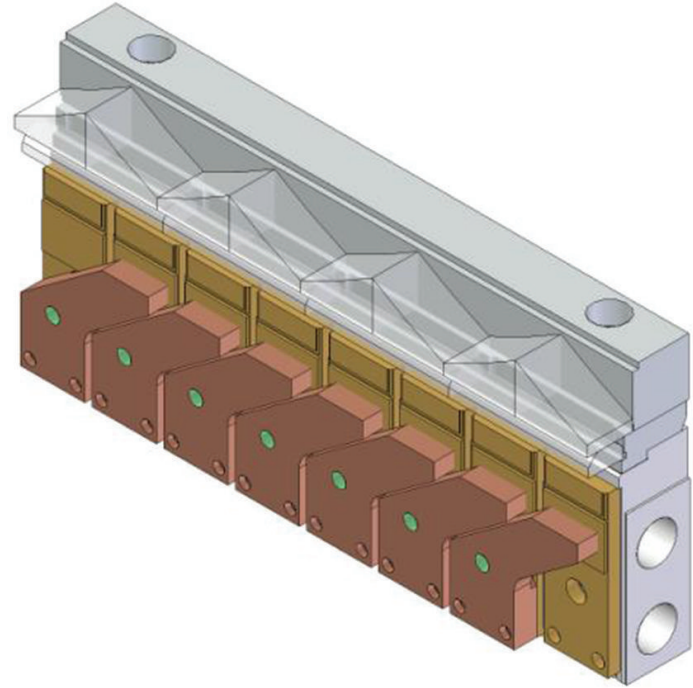

FIGURE 3: $1.6 \mathrm{~kW}$ diode laser: fixing and serial connection with $\mathrm{Cu}-$ diagonal-connectors; FAC-lenses and prisms for beam-crossing.

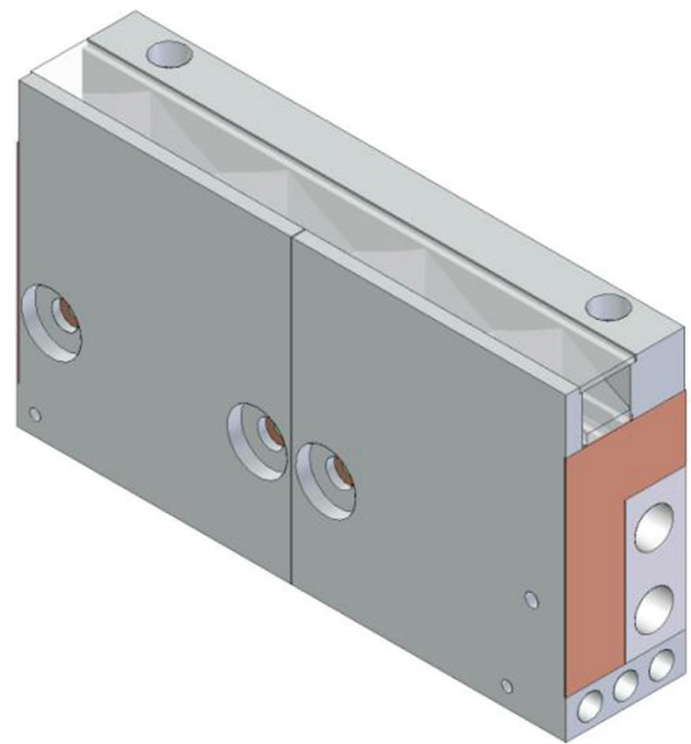

Figure 4: $1.6 \mathrm{~kW}$ diode laser: casing, thin side covers and a protection glass. 


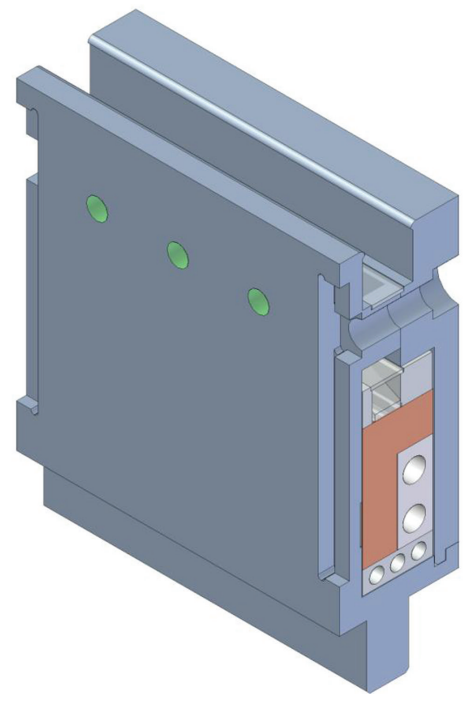

FiguRE 5: 1.6 kW diode laser: assembly into a lower tool.

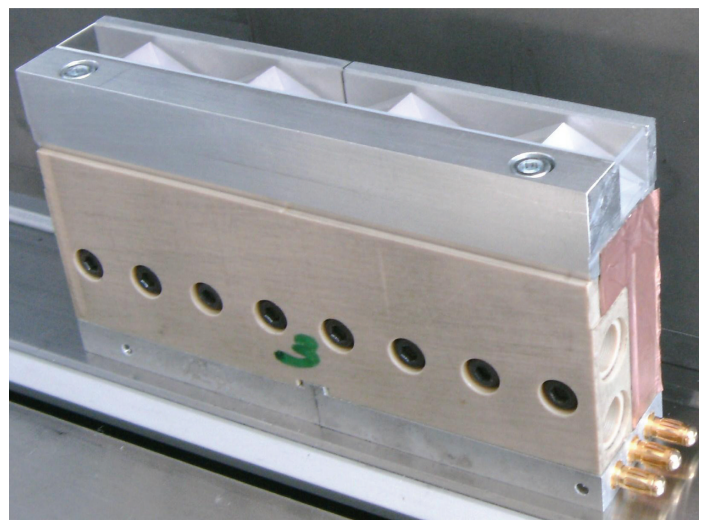

FIgure 6: A finished diode laser with $1.6 \mathrm{~kW}$ for $100 \mathrm{~mm}$ bending length, ready for assembly into the lower tool.

The in- and outlets for the cooling water must be sealed with O-rings. This requires that the lasers are pressed together by plates that are mounted on the ends of the array of lower tools.

Figure 7 shows a complete bending tool for $400 \mathrm{~mm}$ bending length with a laser power of $6.4 \mathrm{~kW}$. For work pieces shorter than $400 \mathrm{~mm}$, the lasers below noncovered tools would emit into free space. To prohibit that, a glider, made of aluminum, is installed on the left hand side of the setup. During every bending operation, this glider is shifted via pneumatics until it touches the work piece. Then laser operation starts.

\section{Operating the Lasers}

A power supply with $30 \mathrm{~kW}$ output power supplies the diode lasers, for a maximum bending length of $1 \mathrm{~m}$. For longer bending lengths, several power supplies can be connected in series to do the supply in a master-slave configuration.

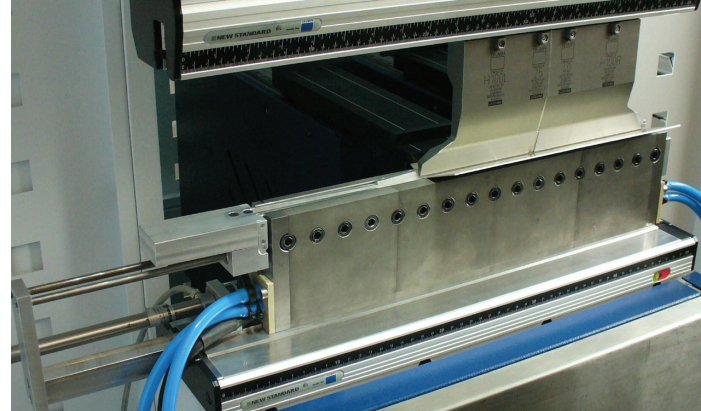

FIGURE 7: $400 \mathrm{~mm}$ laser assisted bending tool in operation. Installed laser power: $6.4 \mathrm{~kW}$.

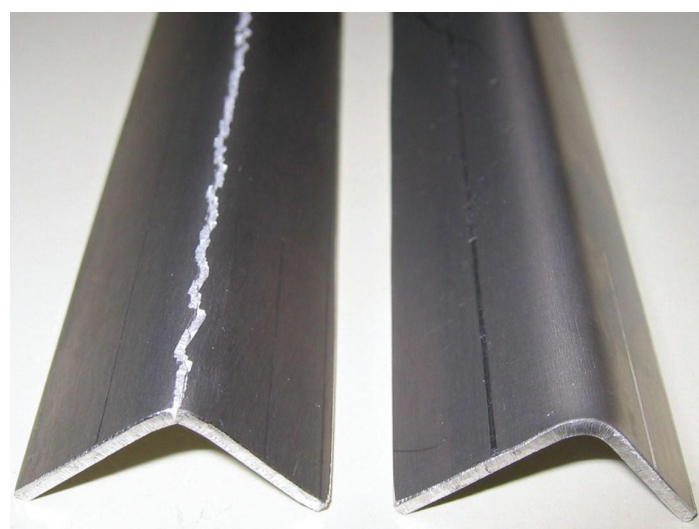

Figure 8: Bending of the Mg-alloy AZ31 without (left) and with (right) laser heating.

For cooling, deionized water at $21^{\circ} \mathrm{C}$ with a flow rate of $3850 \mathrm{l} / \mathrm{h}$ is required for $1 \mathrm{~m}$ bending length at a pressure of up to 9 bar. The cooling capacity can be well below the laser heat losses of $\sim 15 \mathrm{~kW} / \mathrm{m}$ due to a maximum load ratio of $<0.5$.

Dirt falling down from the work piece is removed by a strong flow of pressured air.

\section{Control and Results}

The control is based on time or on the temperature of the work piece, measured by a thermoelement, which is integrated in the upper tool.

First, a small cold bending is performed. Then the press stops, and the laser heating starts. At a predefined temperature or time, the bending process proceeds while the lasers remain on. Usually the temperature rises further during the bending process. In some cases, for example, when the bending has to be done very slowly, a control loop keeps the temperature on a predefined level to avoid damage of the work piece.

Typical heat-up times are in the range of $1-5 \mathrm{~s}$ depending on the thickness and material properties of the work piece. 
The following materials were tested with this process.

(i) Mg-alloys (AZ31, ZE10), thickness is 1-2.5 mm: temperature range is $200-300^{\circ} \mathrm{C}$. Usually the absorption is sufficient to overcome the high heat conductivity high increase of ductility (Figure 8), well suited for laser-assisted bending.

(ii) Al-alloys (7075, Titanal), thickness is $1-2.5 \mathrm{~mm}$; temperature range is $200-300^{\circ} \mathrm{C}$ with high heat conductivity, very low absorption, so an absorbing layer like graphite is necessary, high increase of ductility, but $\sim 20 \%$-decrease of strength in the forming zone.

(iii) Ti-alloys (Titan Grade 2, WL 3.7164), thickness 2-12.7 mm: temperature range $300-600^{\circ} \mathrm{C}$, good absorption, low heat conductivity, appreciable increase of ductility, very well suited for laser assisted bending.

(iv) Steels (M85, St52, Hardox), thickness is $1-3 \mathrm{~mm}$, temperature range is $400-600^{\circ} \mathrm{C}$, good absorption, problems with blue brittleness, very accurate temperature control needed, up to now good results only with the spring steel M85, other steels were successfully bent by Geiger et al. [3].

\section{Conclusion}

We presented a laser-assisted bending system that allows the fast bending of brittle sheet metals by laser heating of the forming zone. This is done with diode lasers that are integrated in the lower bending tools. The power per bending length is $16 \mathrm{~kW} / \mathrm{m}$.

The method was successfully applied to Mg-, Al-, Ti-, and steel-alloys. With the proper processing window, bending of brittle materials become nearly as simple as ordinary cold bending. Welcome side effects are the reduction of the necessary bending force, the reduction of spring back, and sharper edges in the case of materials, that can be bent cold as well.

Possible applications are countless in general engineering, car building, aero space industry, general light weight construction, electronic devices, and in consumption industry.

\section{Acknowledgments}

This project was funded by the company TRUMPF Maschinen Austria and by the Austrian funding association FFG (formerly FFF) under the project title "Laser-Assisted Bending" (Laser-Unterstütztes Gesenk-Biegen, LUGB). The authors are deeply indebted to DI F. Killian, Trumpf GmbH \& Co. KG in Ditzingen/FRG, Dr. A. Hutterer, DI A. Rau, and G. Sperrer, Trumpf Maschinen Austria in Pasching/Linz for valuable scientific adviceand cooperation.

\section{References}

[1] F. Vollertsen, "An analytical model for laser bending," Lasers in Engineering, vol. 2, pp. 261-276, 1994.

[2] D. Schuöcker, C. Zeinar et al., "Laser assisted bending," in Proceedings of the 3rd Laser Assisted Net shape Engineering, pp. 475-482, 2001.

[3] M. Geiger, M. Merklein, and A. Otto, "Laser assisted bending of complex-phase steel," Production Engineering, vol. 2, no. 10, pp. 13-16, 2004.

[4] G. Erbert, A. Bärwolff, J. Sebastian, and J. Tomm, "High-power broad-area diode lasers and laser bars," in High-Power Diode Lasers, R. Diehl, Ed., vol. 78 of Topics Appl. Phys., pp. 173-223, Springer, Berlin, Germany, 2000. 

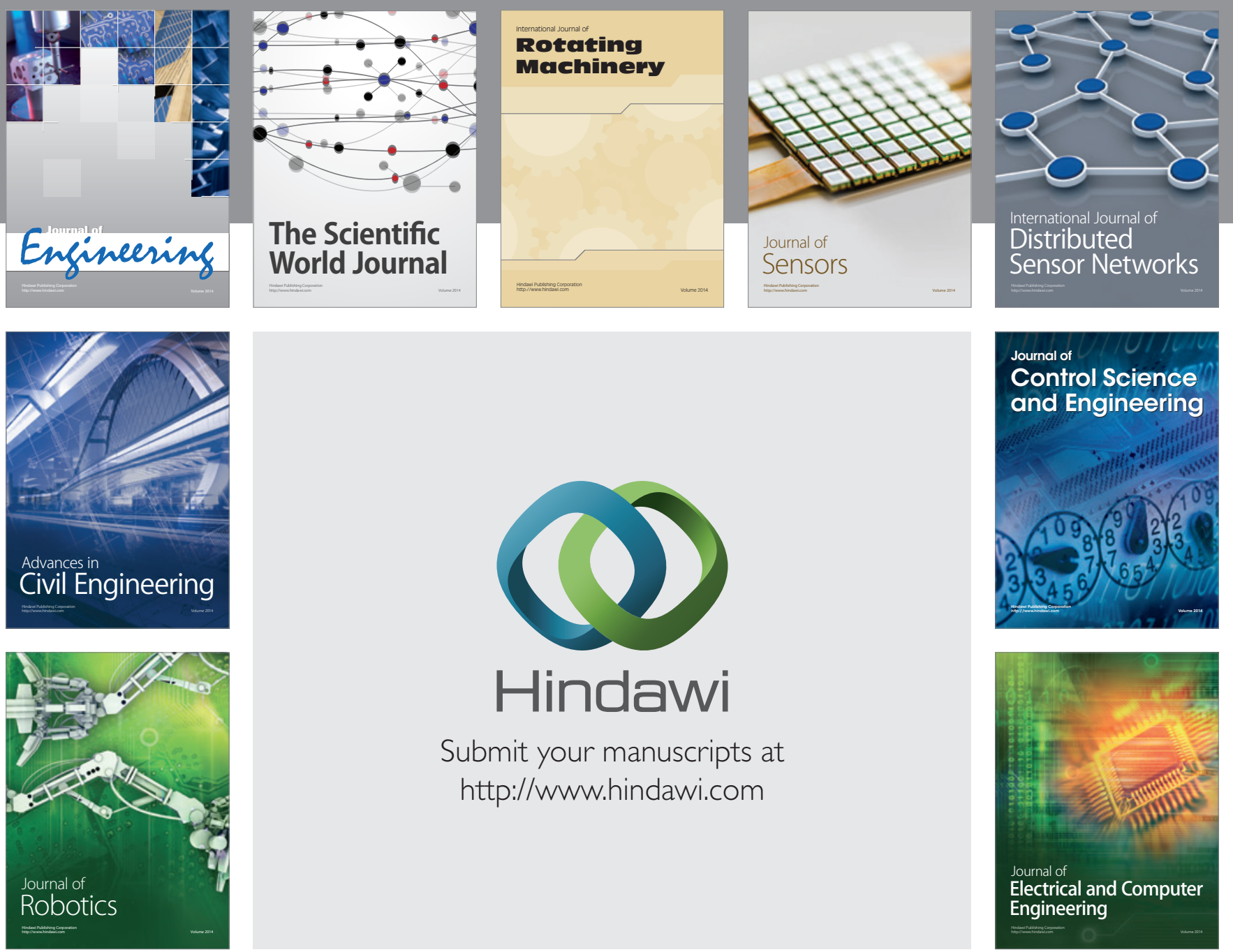

Submit your manuscripts at

http://www.hindawi.com
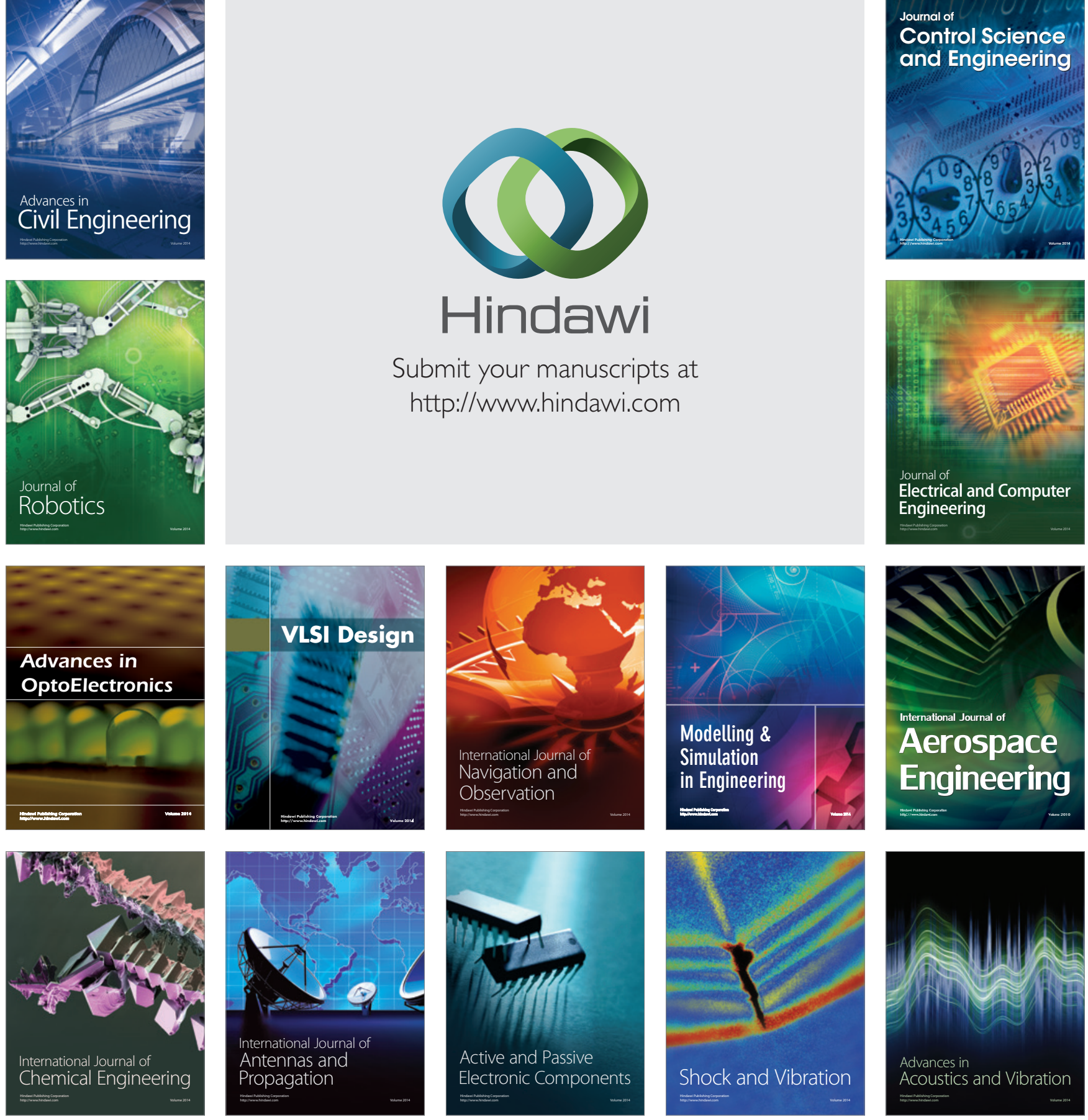